\title{
Genome-wide linkage scan for factors of metabolic syndrome in a Chinese population
}

\author{
Claudia HT Tam¹, Vincent KL Lam¹, Wing-Yee So ${ }^{1}$, Ronald CW Ma' ${ }^{1}$, Juliana CN Chan ${ }^{1,2,3^{*}}$, Maggie CY Ng ${ }^{1,4}$
}

\begin{abstract}
Background: Shared genetic factors may contribute to the phenotypic clustering of different components of the metabolic syndrome (MES). This study aims to identify genetic loci that contribute to individual or multiple factors related to MES.

Results: We studied 478 normoglycemic subjects ascertained through 163 families participating in the Hong Kong Family Diabetes Study. Factor analysis on 15 MES-related traits yielded 6 factors including adiposity factor (body mass index, waist and hip circumferences), insulin factor (fasting insulin and insulin AUC during OGTT), glucose factor (fasting glucose and glucose AUC during OGTT), TC-LDLC factor (total cholesterol and LDL-cholesterol), blood pressure factor (systolic and diastolic blood pressure) and TG-HDLC factor (triglycerides and HDL-cholesterol). Genome-wide linkage analyses were performed on these factors using variance component approach. Suggestive evidence for linkage ( $\mathrm{LOD}=1.24$ - 2.46) were observed for adiposity factor (chromosome 1 at $187 \mathrm{cM}$, chromosome 9 at $34 \mathrm{cM}$ and chromosome 17 at $10 \mathrm{cM}$ ), insulin factor (chromosome 2 at $128 \mathrm{cM}$, chromosome 5 at $21 \mathrm{cM}$ and chromosome 12 at $7 \mathrm{cM}$ ), glucose factor (chromosome 7 at $155 \mathrm{cM}$ ), TC-LDLC factor (chromosome 7 at $151 \mathrm{cM}$ and chromosome 13 at $15 \mathrm{cM}$ ) and TG-HDLC factor (chromosome 7 at $155 \mathrm{cM}$ ).

Conclusions: In summary, our findings suggest the presence of susceptibility loci that influence either single (chromosomes 1, 2, 5, 9, 12, 13 and 17) or multiple factors (chromosome 7) for MES in Hong Kong Chinese without diabetes.
\end{abstract}

\section{Background}

Metabolic syndrome (MES) represents a clustering of multiple metabolic abnormalities, including insulin resistance, glucose intolerance, hyperinsulinemia, dyslipidemia, hypertension, and obesity $[1,2]$. These metabolic factors interact to substantially increase the risk of cardiovascular diseases, chronic kidney disease, and type 2 diabetes (T2D) [3-5]. Similar to figures reported in the US, [6], the prevalence of MES ranges from 10\% to $30 \%$ in Asian populations [7]. In Hong Kong, where 95\% or more of the residents are Han Chinese, the prevalence of MES was $17 \%$ in 2000 [8]. After 6 years of follow up, subjects with MES had 4-5 fold increased risk of new onset of diabetes [9] and 2-3 fold increased risk of heart disease and all-cause mortality [10].

Principal component factor analysis (PCFA) is a multivariate statistical technique used to extract a set of

\footnotetext{
* Correspondence: jchan@cuhk.edu.hk

'Department of Medicine and Therapeutics, The Chinese University of Hong Kong, The Prince of Wales Hospital, Shatin, Hong Kong SAR, China
}

latent or underlying independent factors from a large number of inter-correlated variables. Edwards et al. [11] firstly used factor analysis to understand the underlying relationships among metabolic risk variables. In the past decade, we $[12,13]$ and others have reported the composition of multiple factors and their overlapping nature in subjects with MES [14-18].

In a working population of Hong Kong Chinese, we used structural equation modelling and identified age, family history and obesity as the major explanatory variables for all components of MES including insulin resistance [13]. In the Hong Kong Family Diabetes Study (HKFDS), we further demonstrated that all metabolic traits of MES including adiposity, blood pressure, lipids, insulin resistance and beta-cell function were highly heritable (heritability $=0.45-0.63$ ) [19]. Subsequent genome-wide linkage analyses of this family-based cohort revealed linkage at multiple chromosomal regions for diabetes, MES and/or related quantitative traits $[20,21]$. 
Previous studies in Caucasian populations have suggested that different factors of MES may be regulated by shared genetic factors which may partly explain the clustering of MES factors within an individual [22,23]. In this study, we applied PCFA to identify six independent factors of MES (adiposity, insulin, glucose, TCLDLC, blood pressure and TG-HDLC factors). Then we tested for the hypothesis if shared or independent genetic factors contribute to these MES factors by performing genome-wide linkage analysis in 478 normoglycemic subjects from 163 families ascertained from the HKFDS.

\section{Results}

The clinical characteristics of 478 normoglycemic family members in 163 families are summarized in Table 1. Table 2 shows the pairwise Pearson product moment correlation coefficients of the 15 MES-related quantitative traits. The adiposity traits were highly correlated with each other $(r>0.76)$. In addition, body mass index (BMI) and waist circumference (WC) showed moderate correlations with all other traits $(r=0.24$ to 0.44$)$. On the other hand, HDL-cholesterol (HDLC) showed moderate inverse correlations with other traits $(r=-0.13$ to -0.39), except for total cholesterol (TC).

In the factor analysis of these 15 traits, six factors were extracted and cumulatively explained $82 \%$ of the total variance (Table 3 ). The six extracted factors are consistent with the inter-relationship among closely

\begin{tabular}{|c|c|}
\hline Characteristics & Value \\
\hline N & 478 \\
\hline Male/female & 199/279 \\
\hline Age (years ) & $37 \pm 13$ \\
\hline Body mass index $\left(\mathrm{kg} / \mathrm{m}^{2}\right)$ & $23.8 \pm 4.1$ \\
\hline Waist circumference $(\mathrm{cm})$ & $78 \pm 10$ \\
\hline Hip circumference $(\mathrm{cm})$ & $96 \pm 8$ \\
\hline Fasting Insulin (pmol/l) & $46(43-48)$ \\
\hline Insulin AUC 0 - 30 minutes (pmol/l) & $6000(5668-6352)$ \\
\hline Insulin AUC 0 - 120 minutes (pmol/l) & $38897(36954-40964)$ \\
\hline Fasting plasma glucose (mmol/l) & $4.9 \pm 0.5$ \\
\hline Plasma glucose AUC 0 - $30 \mathrm{~min}(\mathrm{mmol} / \mathrm{l})$ & $202.1 \pm 29.5$ \\
\hline Plasma glucose AUC 0 - $120 \mathrm{~min}(\mathrm{mmol} / \mathrm{l})$ & $887.4 \pm 199.4$ \\
\hline Systolic blood pressure $(\mathrm{mmHg})$ & $120 \pm 17$ \\
\hline Diastolic blood pressure $(\mathrm{mmHg})$ & $73 \pm 12$ \\
\hline Total cholesterol (mmol/l) & $5.0 \pm 1.0$ \\
\hline LDL cholesterol (mmol/l) & $3.0 \pm 0.9$ \\
\hline Triglyceride (mmol/l) & $1.01(0.96-1.06)$ \\
\hline HDL cholesterol $(\mathrm{mmol} / \mathrm{l})$ & $1.4 \pm 0.4$ \\
\hline
\end{tabular}

Data are shown as mean \pm SD or geometric mean $(95 \% \mathrm{CI})$. AUC, Area under curve related traits (Table 2) and are interpreted as follows: Factor 1 refers to "adiposity factor", with high positive loadings of BMI, WC and hip circumference ( $\mathrm{HC}$ ); factor 2 refers to "insulin factor" with strong positive correlations with plasma insulin (PI) areas under the curve (AUC) for 0 - $30 \mathrm{~min}$ and PI AUC for 0 - $120 \mathrm{~min}$ and moderate positive correlation with fasting PI; factor 3 refers to "glucose factor" with high positive correlations among fasting plasma glucose (PG), PG AUC for 0 - 30 min and PG AUC for 0 - $120 \mathrm{~min}$; factor 4 refers to "TC-LDLC factor", dominated by a high positive correlation between TC and LDL-cholesterol (LDLC); factor 5 refers to "BP factor", with large positive loadings for systolic and diastolic blood pressure (SBP and DBP); factor 6 refers to "TG-HDLC factor", with strong but inverse relationship between triglycerides (TG) and HDLC. All six factors showed moderate to high heritabilities, ranging from 29 to $67 \%$ (Table 3).

In the variance component multipoint linkage analyses, we observed suggestive evidence of linkages (empirical p-value $<0.01$ ) on chromosomes 1,9 and 17 for adiposity factor (LOD = $1.92-2.46$ ), chromosomes 2,5 and 12 for insulin factor (LOD = $1.61-2.23$ ), chromosome 7 for glucose factor (LOD $=2.16$ ) and TGHDLC factor $($ LOD $=1.96)$, as well as chromosomes 7 and 13 for TC-LDLC factor (LOD = 1.24 - 1.43) (Table 4 and Figure 1). Of note, the chromosome 7 region at $155 \mathrm{cM}$ demonstrated a clustering of linkage signals for glucose, TC-LDLC and TG-HDLC factors. When the linkage results from PCFA were compared to that of their respective individual components (see Additional file 1), we observed consistent linkages for individual components for adiposity factor on chromosomes 1 and 9 and for glucose factor on chromosome 7, with the linkage signals from PCFA stronger than the individual components (Figure 2). On the other hand, the linkage signals for PCFA factors in other regions were modest compared to the varied linkage signals strength for individual components (see Additional file 1).

\section{Discussion}

This genome scan analysis was performed in normoglycemic subjects in the HKFDS. The original study consists of 913 first degree relatives recruited from 179 families with predominantly young-onset diabetes. In this cohort, $53 \%$ of the probands and $25 \%$ of the siblings had MES. All metabolic traits of MES demonstrated high heritability estimates ranging from 0.45 to 0.63 [19]. In a linkage analysis based on 64 families with 126 affected sib-pairs segregating the diabetes trait, we identified suggestive linkage to chromosomes 1, 4, 6 and 12 [20]. In a follow up analysis using the entire familybased cohort, we reported suggestive linkage of MES traits to chromosomes 1,2 and 16 [21]. 
Table 2 Pearson product moment correlation coefficients of the 15 metabolic syndrome-related traits in normoglycemic family members

\begin{tabular}{|c|c|c|c|c|c|c|c|c|c|c|c|c|c|c|c|}
\hline Phenotype & 1 & 2 & 3 & 4 & 5 & 6 & 7 & 8 & 9 & 10 & 11 & 12 & 13 & 14 & 15 \\
\hline 1. BMI & - & & & & & & & & & & & & & & \\
\hline 2. WC & 0.854 & - & & & & & & & & & & & & & \\
\hline 3. $\mathrm{HC}$ & 0.825 & 0.776 & - & & & & & & & & & & & & \\
\hline 4. Fasting PI & 0.404 & 0.319 & 0.307 & - & & & & & & & & & & & \\
\hline 5. PI AUC $0-30 \mathrm{~min}$ & 0.291 & 0.275 & 0.281 & 0.475 & - & & & & & & & & & & \\
\hline 6. PI AUC 0 - $120 \mathrm{~min}$ & 0.364 & 0.348 & 0.295 & 0.530 & 0.717 & - & & & & & & & & & \\
\hline 7. Fasting PI & 0.353 & 0.419 & 0.253 & 0.174 & -0.068 & 0.095 & - & & & & & & & & \\
\hline 8. PG AUC $0-30 \mathrm{~min}$ & 0.266 & 0.347 & 0.143 & 0.143 & 0.184 & 0.241 & 0.617 & - & & & & & & & \\
\hline 9. PG AUC $0-120 \mathrm{~min}$ & 0.360 & 0.400 & 0.192 & 0.180 & -0.014 & 0.327 & 0.576 & 0.718 & - & & & & & & \\
\hline 10. SBP & 0.367 & 0.438 & 0.278 & 0.096 & 0.027 & 0.074 & 0.329 & 0.309 & 0.354 & - & & & & & \\
\hline 11. DBP & 0.386 & 0.419 & 0.246 & 0.190 & 0.099 & 0.130 & 0.234 & 0.241 & 0.288 & 0.741 & - & & & & \\
\hline 12. TC & 0.242 & 0.306 & 0.141 & 0.023 & -0.007 & 0.060 & 0.264 & 0.261 & 0.239 & 0.165 & 0.112 & - & & & \\
\hline 13. LDL & 0.276 & 0.354 & 0.200 & 0.015 & -0.003 & 0.069 & 0.290 & 0.264 & 0.236 & 0.154 & 0.109 & 0.930 & - & & \\
\hline 14. TG & 0.303 & 0.361 & 0.203 & 0.268 & 0.256 & 0.314 & 0.275 & 0.302 & 0.299 & 0.169 & 0.170 & 0.287 & 0.199 & - & \\
\hline 15. HDL & -0.298 & -0.391 & -0.259 & -0.169 & -0.153 & -0.250 & -0.240 & -0.173 & -0.198 & -0.139 & -0.157 & 0.105 & -0.131 & -0.387 & - \\
\hline
\end{tabular}

Table 3 Factor loadings and variance explained by the factors after varimax rotation in the PCFA model

\begin{tabular}{|c|c|c|c|c|c|c|}
\hline Phenotype/Interpretation & $\begin{array}{l}\text { Factor } 1 \\
\text { Adiposity }\end{array}$ & $\begin{array}{l}\text { Factor } 2 \\
\text { Insulin }\end{array}$ & $\begin{array}{l}\text { Factor } 3 \\
\text { Glucose }\end{array}$ & $\begin{array}{c}\text { Factor } 4 \\
\text { TC-LDL }\end{array}$ & $\begin{array}{c}\text { Factor } 5 \\
\text { Blood Pressure }\end{array}$ & $\begin{array}{l}\text { Factor } 6 \\
\text { TG-HDL }\end{array}$ \\
\hline Body mass index $\left(\mathrm{kg} / \mathrm{m}^{2}\right)^{\text {a }}$ & 0.87 & 0.24 & 0.15 & 0.10 & 0.16 & -0.15 \\
\hline Waist circumference $(\mathrm{cm})^{a}$ & 0.87 & 0.22 & 0.17 & 0.09 & 0.16 & -0.19 \\
\hline Hip circumference $(\mathrm{cm})^{\text {a }}$ & 0.93 & 0.13 & 0.06 & 0.06 & 0.10 & -0.05 \\
\hline Fasting Insulin (pmol/l) ${ }^{a}$ & 0.23 & 0.68 & 0.09 & 0.03 & 0.17 & -0.12 \\
\hline Insulin AUC $0-30$ minutes $(\mathrm{pmol} / \mathrm{l})^{\mathrm{b}}$ & 0.13 & 0.90 & -0.03 & -0.01 & 0.00 & -0.02 \\
\hline Insulin AUC $0-120$ minutes $(\mathrm{pmol} / \mathrm{l})^{\mathrm{b}}$ & 0.16 & 0.86 & 0.21 & 0.02 & 0.03 & -0.15 \\
\hline Fasting plasma glucose $(\mathrm{mmol} / \mathrm{l})^{a}$ & 0.23 & -0.09 & 0.76 & 0.08 & 0.06 & -0.13 \\
\hline Plasma glucose AUC $0-30 \mathrm{~min}(\mathrm{mmol} / \mathrm{l})^{a}$ & 0.00 & 0.21 & 0.87 & 0.05 & 0.05 & 0.01 \\
\hline Plasms glucose AUC $0-120 \mathrm{~min}(\mathrm{mmol} / \mathrm{l})^{a}$ & 0.10 & 0.12 & 0.84 & 0.03 & 0.12 & -0.13 \\
\hline Systolic blood pressure $(\mathrm{mmHg})^{a}$ & 0.19 & 0.00 & 0.15 & -0.05 & 0.88 & -0.03 \\
\hline Diastolic blood pressure $(\mathrm{mmHg})^{\text {a }}$ & 0.12 & 0.15 & 0.04 & -0.02 & 0.91 & -0.06 \\
\hline Total cholesterol $(\mathrm{mmol} / \mathrm{l})^{a}$ & 0.05 & 0.03 & 0.06 & 0.99 & -0.01 & 0.04 \\
\hline LDL cholesterol $(\mathrm{mmol} / \mathrm{l})^{\mathrm{b}}$ & 0.13 & 0.00 & 0.07 & 0.94 & -0.06 & -0.08 \\
\hline Triglyceride $(\mathrm{mmol} / \mathrm{l})^{a}$ & 0.11 & 0.20 & 0.14 & 0.26 & 0.10 & -0.79 \\
\hline $\mathrm{HDL}$ cholesterol $(\mathrm{mmol} / \mathrm{l})^{\mathrm{b}}$ & -0.18 & -0.06 & -0.09 & 0.16 & 0.00 & 0.87 \\
\hline Eigenvalue & 4.72 & 1.99 & 1.73 & 1.57 & 1.27 & 1.09 \\
\hline Total variance (\%) & 31.45 & 13.29 & 11.55 & 10.44 & 8.46 & 7.28 \\
\hline Cumulative variance (\%) & 31.45 & 44.74 & 56.29 & 66.73 & 75.18 & 82.46 \\
\hline Heritabilities & 61.69 & 55.62 & 28.58 & 67.03 & 64.15 & 64.00 \\
\hline
\end{tabular}

${ }^{a}$ and ${ }^{b}$ indicates natural logarithm and square root transformation. Factor loadings $>0.4$ are highlighted in boldface.

To delineate whether the linkage signals observed in our previous linkage studies affect single or multiple metabolic factors, we genotyped additional microsatellite markers within these previously linked regions. Only subjects with normoglycemia were analyzed in the present study in order to avoid possible modifying effect of diabetes on the metabolic traits. Using PCFA, we identified six discrete factors loaded with closely related variables, namely adiposity, insulin, glucose,
TC-HDLC, TC-LDLC and BP. Principal component factor analysis (PCFA) aimed to reduce a set of observable variables to a small number of latent factors that account for the correlations among observed variables. This analysis strategy compensates the problem associated with multiple comparisons and increases the power significantly [24]. For example, only one test of linkage analysis was applied on the adiposity factor in our study instead of three linkage tests on the 
Table 4 Regions showing nominal evidence of multipoint linkage (empirical p-value $<0.01$ ) to the factors

\begin{tabular}{|c|c|c|c|c|c|c|}
\hline Factors & Interpretation & Chr & Position (cM) $^{a}$ & Flanking markers & LOD & Empirical P-value \\
\hline \multirow[t]{3}{*}{1} & Adiposity & 1 & 187 & DIS466 - D1S202 & 2.22 & 0.0022 \\
\hline & & 9 & 34 & GATA187D09 - D9S925 & 1.92 & 0.0038 \\
\hline & & 17 & 10 & D17S1308 - D17S1298 & 2.46 & 0.0013 \\
\hline \multirow[t]{3}{*}{2} & Insulin & 2 & 128 & D2S2972 - D2S1328 & 2.23 & 0.0018 \\
\hline & & 5 & 21 & D5S2505 - D5S1486 & 1.61 & 0.0070 \\
\hline & & 12 & 7 & D12S372 & 1.92 & 0.0037 \\
\hline 3 & Glucose & 7 & 155 & D7S1804 - GATA104 & 2.16 & 0.0003 \\
\hline \multirow[t]{2}{*}{4} & TC-LDLC & 7 & 151 & D7S1804 - GATA104 & 1.24 & 0.0090 \\
\hline & & 13 & 15 & D13S787 - ATA5A09 & 1.43 & 0.0064 \\
\hline 6 & TG-HDLC & 7 & 155 & D7S1804 - GATA104 & 1.96 & 0.0020 \\
\hline
\end{tabular}

${ }^{a}$ Marker positions are indicated as CM from pter in the deCODE Map.

corresponding individual quantitative traits including BMI, WC, and HIP.

Many of our linkage signals were linked to chromosomal regions observed by other genome scans for hypertension [25,26], fasting insulin [27,28], dyslipidemia [29], visceral fat area [30] and/or low metabolic rates [31]. Interestingly, several of these regions were also linked to obstructive sleep apnoea [32] which is closely associated with obesity. Additional file 2, table S2 summarized the linkage findings in the present and other previous studies.

Despite excluding subjects with diabetes, we found significant linkage of adiposity factor to chromosome 1q at the $187 \mathrm{cM}$ region. The linkage of chromosome 1q 21-25 region to type 2 diabetes has been replicated in at least 8 independent populations suggesting that this region is likely to harbor major gene(s) for diabetes and/ or MES [33]. The overlapping nature of this region linked to diabetes, MES and adiposity traits in our families suggests that genetic variants in this region may interact with other factors to give rise to diabetes. In addition, we found regions linked to adiposity on chromosomes 9 (34 cM) and $17(10 \mathrm{cM})$. These regions were close to the linkage signals reported in other genome scans of MES or related traits. In the GIFT Study, a significant evidence for a region on chromosome 17 (29 - $58 \mathrm{cM})$ linked to T2D was reported [34]. This region contains a large number of genes which may influence various transcription and signaling pathways in energy metabolism. These include glucagon-like peptide 2 receptor $(G L P 2 R)$, mitogen-activated protein kinases (MAPK) MAP2K4 and MAP2K3; transcription factors, (STAT) $5 A$ and $S T A T 5 B$, neuropeptide pancreatic polypeptide 2 ( $P P Y 2)$; complement $\mathrm{C} 1 \mathrm{q}$ receptor protein (C1QBP); lipoxygenase (LO) gene family, ALOX12 and $A L O X 15$ [27]. The other regions on chromosome 9 linked to adiposity factor in our cohort were also significant in other genome scans for hypertension [26], familial dyslipidemia [29], visceral fat area [30] and HDLC $[30,35]$ in other populations.
In this analysis, the insulin factor was linked to the $128 \mathrm{cM}$ of chromosome 2. Interestingly, an adjacent region at 94-118 cM has been reported in several genome scans for hypertension in both Caucasian and African populations $[26,36]$. This region harbors a number of genes which regulate blood pressure and vascular reactivity such as the $\alpha 2 \beta$ adrenergic receptor gene, a key component of the sympathetic nervous system, SCN7A of the sodium channel and NOSTRIN which is related to the NO pathways [36].

The other region of interest is chromosome 5 at 21 $\mathrm{cM}$ which was also linked to the insulin factor. In a recent 2-dimensional genome scan for hypertension, novel epistatic loci was identified notably on chromosome 5q13.14 which interact with chromosomes 9, 11, 15, 16 and 19 [37]. In the Hypertension Genetic Epidemiology Network (HyperGEN) of the Family Blood Pressure Program, a genome scan also identified a linkage signal on chromosome 5 at $20 \mathrm{cM}$ with a LOD score of 2.36 in European Americans. Both diabetes and hypertension are heterogeneous disorders with multiple and interacting aetiologies, including activation of stress hormonal systems, hyperinsulinemia, abnormal vascular smooth muscle cellular growth and sodium and water retention [38]. To this end, subjects with genetic predisposition to hyperinsulinemia are prone to develop hypertension, which may be accelerated by obesity-associated insulin resistance. In support of this notion, the candidate genes located in this region include $\beta 2$-adrenergic receptor $(A D R B 2)$, natriuretic peptide receptor $C$ (NRP3) and islet-1 (ISL1). ADRB2 is involved in vasodilation [39] while NRP3 inhibits adenyl cyclase [40], both of which are implicated in blood pressure control. The other candidate, ISL1, is a transcription factor that regulates insulin gene expression in the pancreatic islets [41].

The $155 \mathrm{cM}$ region of chromosome 7 was linked to both glucose and lipid factors (TC-LDLC and TGHDLC). Of note, nearby regions at 109-123 cM and 134 cM have been linked to low HDLC and visceral fat in 


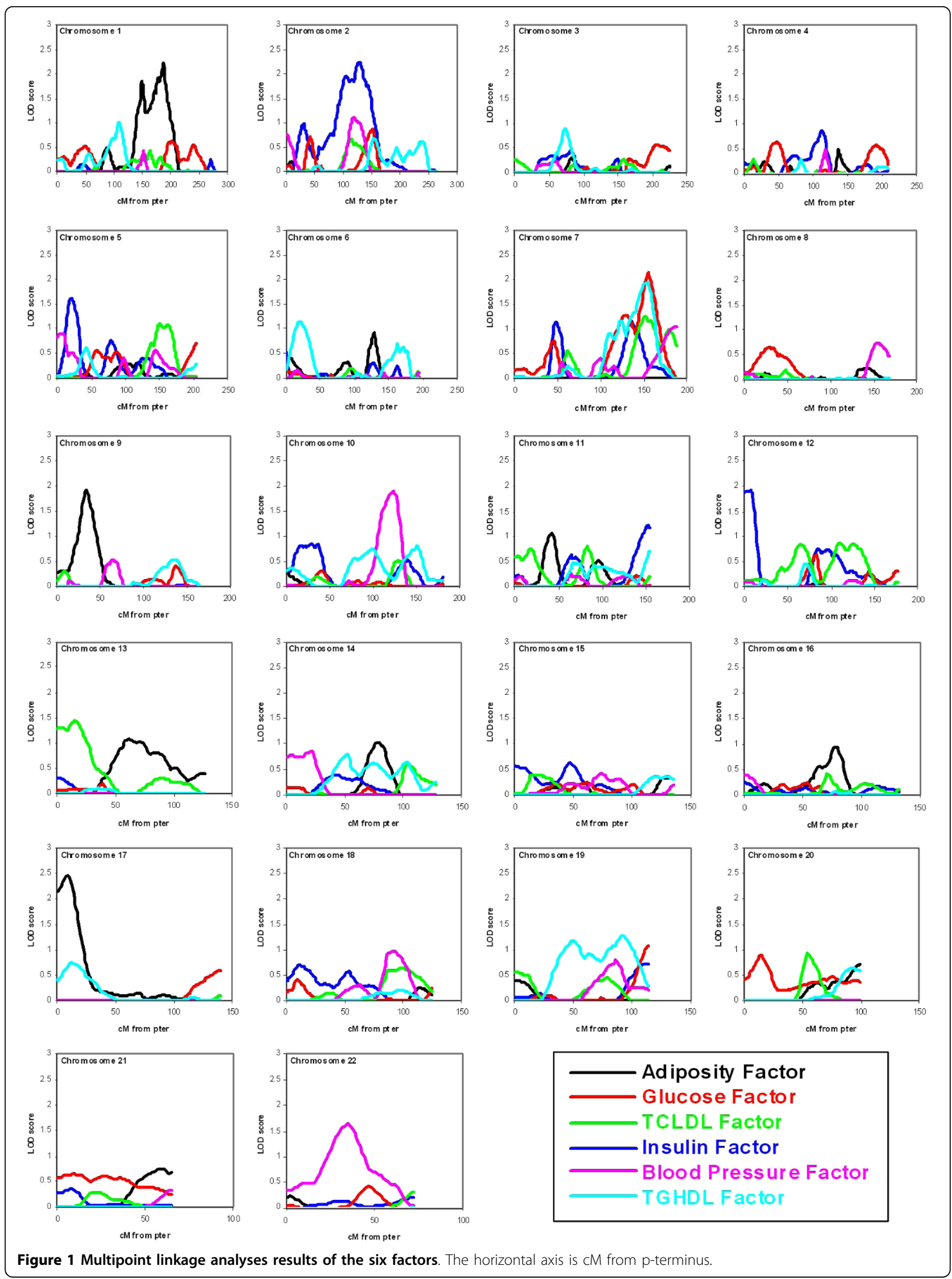



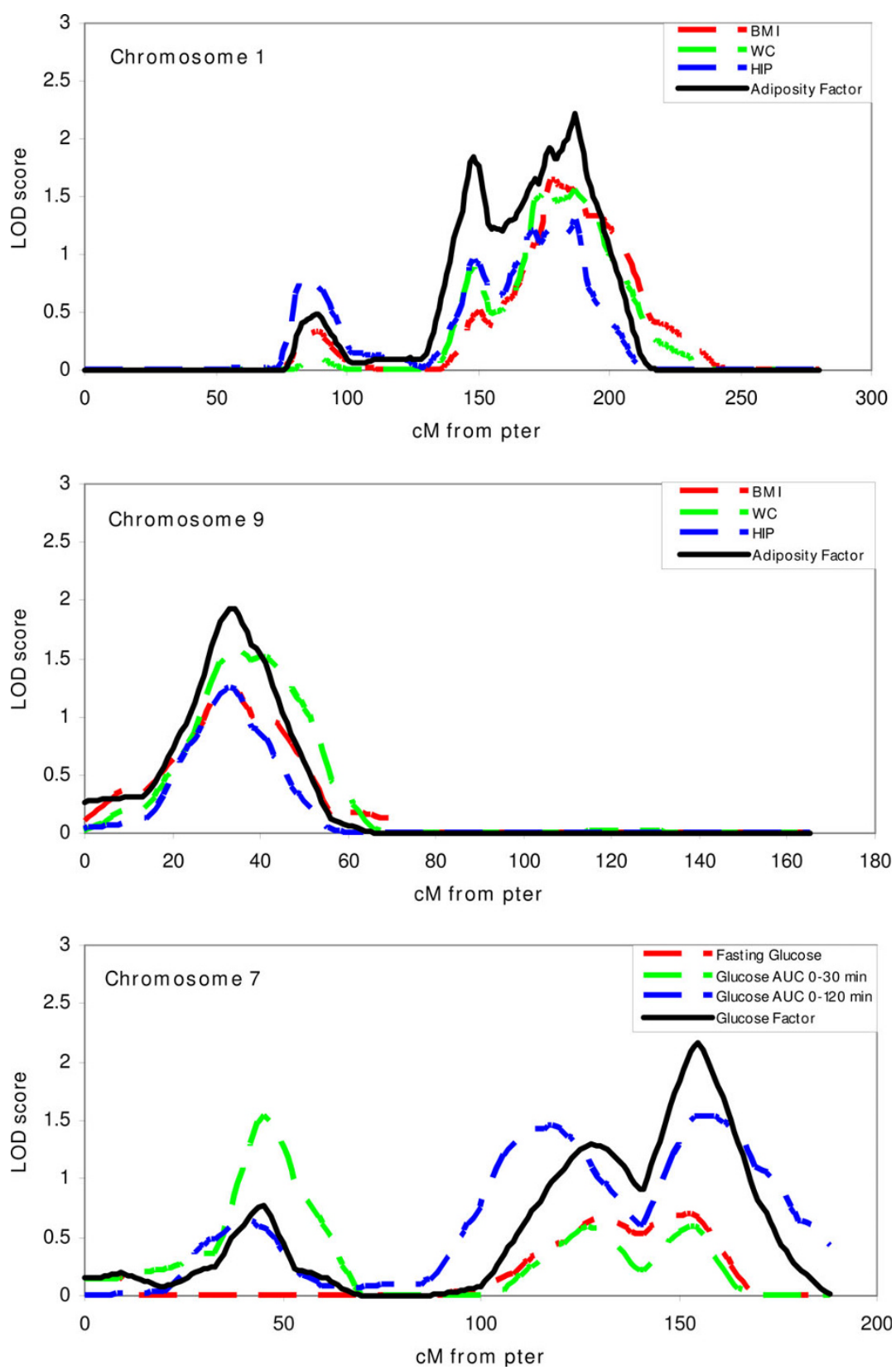

Figure 2 Comparisons of multipoint linkage analyses results for metabolic factors and its individual components. a) Adiposity factor vs BMI, WC and HC on chromosome 1. b) Adiposity factor vs BMI, WC and HIP on chromosome 9. c) Glucose factor vs fasting plasma glucose (PG), PG AUC 0-30 minutes and PG AUC 0-120 minutes on chromosome 7. The horizontal axis is cM from p-terminus.

other populations [30]. Ectopic especially visceral fat plays pivotal role in insulin resistance mainly through increased production of free fatty acids and cytokines. Insulin resistance in turn can lead to non-suppression of lipolysis and increased hepatic glucose production leading to hyperglycemia and dyslipidemia as components of the MES [42].

In this analysis, we identified six factors during factor analysis whereas other studies reported three to four factors only $[22,23,43]$. In the latter case, the insulin variables are commonly loaded on the same factor as adiposity variables. Our seemingly discrepant results might be due to population differences. For example, the study populations reported by Tang et al. [23] and Arya et al. [22] were substantially more obese (mean $\mathrm{BMI}=27.6-28$ and $29.1 \mathrm{~kg} / \mathrm{m}^{2}$, respectively) than our cohort $(B M I=23.8 \mathrm{~kg} /$ $\mathrm{m}^{2}$ ). Since hyperinsulinemia and insulin resistance are mainly found in obese subjects, correlation between 
obesity and insulin resistance is likely to be more robust in an obese than a relatively lean population, such as Chinese.

Moreover, the nature and number of metabolic variables used to generate composite factors of the MES vary substantially across studies. While Bossé [43] and Arya [22] included eight MES-related variables, we included fifteen variables in our analysis. In the former studies [43,22], only TG and HDLC were used as the lipid variables and no oral glucose tolerance test (OGTT) data were presented. By contrast, we included four variables (TC, TG, LDLC and HDLC) to quantify dyslipidemia and included AUC for PG and PI during OGTT at 0-30 min and 0-120 min for insulin secretion. This comprehensive phenotypic dataset allows us to identify two blood lipid factors and segregate insulin resistance factor into its glucose and insulin components, which can have different biological determinants.

There are several limitations to this study. Firstly, we examined normoglycemic subjects only in order to exclude the impact of diabetes and medications on the measures of metabolic traits. Although such exclusion may reduce sample size and study power, our results in this subgroup analysis accord with our previously reported linkages to type 2 diabetes and individual MES-related traits in 1q21-25 regions [20,21], along with reports from other populations [33]. Secondly, in the era of genome-wide association studies where reproducible common genetic variants are successfully identified in complex diseases, there are fewer successful examples for discovering complex disease genes using the linkage approach alone $[44,45]$. However, linkage results are complementary and can be used to prioritize the linkage regions for investigation and follow up in genome-wide association and resequencing studies. This is exemplified by the discovery of TCF7L2 gene with type 2 diabetes $[44,46]$. Indeed, genome-wide linkage approach remains essential until high throughput technology that allows association analysis of both rare and common variants at a affordable cost becomes available [47].

\section{Conclusions}

In conclusion, in a family-based cohort of normoglycemic subjects ascertained through probands with predominantly young onset diabetes, we found suggestive linkages to adiposity, insulin, glucose and lipid factors on chromosomes 1, 2, 5, 7, 9, 12, 13 and 17. Some of these regions overlap or in close proximity to other genome scans of MES traits. With increasing understanding of the pathogenesis of MES and related traits, exploration of these regions and their interactions, including epigenetics, will provide important insights into the nature of these interacting pathways and their relationships with clinical presentations, thereby bringing personalized diagnosis and therapy closer to reality.

\section{Methods \\ Subjects}

The study design, ascertainment, inclusion criteria and phenotyping of the HKFDS have been described elsewhere [20]. Briefly, 478 normoglycemic individuals (42\% men) were selected from 163 families consisting of siblings, parents, spouses, and offspring ( $>16$ years) ascertained through a proband with T2D. Patients with clinical or autoimmune type 1 diabetes and families with known maturity-onset diabetes of the young or mitochondrial DNA nucleotide 3243 A > G mutations were excluded. All first degree relatives underwent extended phenotyping including 75 gram OGTT and had complete phenotypic data for 15 MES traits. The average family size was $3(2-4)$ (median (interquartile range)) members. Written informed consent was obtained from all participating subjects. This study was approved by the Clinical Research Ethics Committee of the Chinese University of Hong Kong.

\section{Clinical studies}

Using a standardized protocol, all family members were examined after at least 8 hours of overnight fast. They underwent full clinical examination and completed a questionnaire on personal, family, medical and lifestyle histories. Anthropometric parameters including body weight and height, WC and $\mathrm{HC}, \mathrm{SBP}$ and DBP were measured. Fasting blood samples were collected for measurement of PG, PI, lipid profile (TC, TG, HDLC and LDLC) and DNA extraction. AUC for PG and PI at OGTT 0-30 min, 0-120 min were calculated using the trapezoid rule.

\section{Genotyping}

Detailed information on PCR conditions, genotyping procedure and quality control have been described [20]. Briefly, we made use of the Human Screening Set, version 10 for the previous genome scans. A total of 355 microsatellite markers (Research Genetics, Huntsville, AL) were genotyped across all 22 autosomes. The average spacing between markers was $10 \mathrm{cM}$, and average heterozygosity was $71 \%$. In this analysis, 70 additional microsatellite markers were genotyped at chromosomes $1,2,4,5,6,10,12$ and 16 to delineate whether the linkage signals observed in our previous linkage studies for diabetes, MES and its components [20,21] affect single or multiple metabolic factors. Genetic relationships among family members were checked by programs RELPAIR [48] and PREST (Pedigree Relationship statistical Test) [49], and corrected. Mendelian errors and potential genotyping errors were checked by 
PEDCHECK (version 1.1) [50] and MERLIN (version 1.01) [51], respectively, and removed.

\section{Statistical analysis}

Data were transformed using natural logarithm (BMI, WC, HIP, SBP, DBP, TC, TG, fasting PG, fasting PI, PG AUC for $0-30 \mathrm{~min}$ and PG AUC for $0-120 \mathrm{~min}$ ), or square root (PI AUC for 0 - 30 minutes, PI AUC for 0 120 minutes, HDLC and LDLC) due to skewed distributions. Outliers $(<0.3 \%)$ with values greater than or equal to 4 standard deviations from the mean were removed. Data were then standardized to zero mean and unit variance by multiple linear regression models with age and sex as covariates.

In the factor analysis model, the amount of variance contributed by each factor was evaluated by eigenvalues, which represent the sum of the squared factor loadings. In the present study, factors with eigenvalues $\geq 1.0$ were extracted. We then applied varimax rotation method to achieve a simple structure which showed improved interpretability of factors that were consistent with the underlying biological processes. Traits with factor loadings $\geq 0.40$ in absolute value were used to interpret and characterize the factor structures. Finally, a factor score, which was the estimated values of underlying factor, was calculated for each individual based on the factor loadings and the values of observed phenotypes [23]. The factor analysis (using the PROC FACTOR procedure) and other statistical analyses were performed in SAS v.9.1 (SAS Institute, Cary, NC, USA) unless specified otherwise.

Multipoint variance components linkage analyses implemented in SOLAR v.2.0 [52] were conducted on the factor scores obtained from PCFA to identify linkage for each factor. Estimated heritability for each factor was also reported which estimated the proportion of total variance attributed by the additive genetic variance. To estimate our evidences of linkages, empirical p-values were obtained through the simulation of 10,000 replications of a fully informative marker under the null hypothesis of no linkage between marker and phenotype using SOLAR. A LOD score $\geq 3.0$ was considered as significant evidence of linkage.

Additional file 1: Contains supplementary table 1 - Comparisons of multipoint linkage analyses results for other metabolic factors and its

individual components

Click here for file

[http://www.biomedcentral.com/content/supplementary/1471-2156-1114-S1.DOC ]

Additional file 2: Contains supplementary table 2 - Supplementary Table 2: Summary of linkage findings in the present and other previous studies.

Click here for file

[http://www.biomedcentral.com/content/supplementary/1471-2156-1114-S2.DOC]

\section{Acknowledgements}

Special thanks are extended to Ms. Cherry Chiu, our nursing officer and her team in recruiting and phenotyping all family members. We also thank all subjects for participating in the study. The work was supported by the Central Allocation of the Research Grant Committee of the Hong Kong Government, supplementary grant of the Chinese University of Hong Kong, Hong Kong Foundation for Research and Development, NIH-supported International Chromosome 1q Consortium and the Li Ka Shing Institute of Health Sciences.

\section{Author details}

'Department of Medicine and Therapeutics, The Chinese University of Hong Kong, The Prince of Wales Hospital, Shatin, Hong Kong SAR, China. ${ }^{2} \mathrm{Li}$ Ka Shing Institute of Health Sciences, The Chinese University of Hong Kong, The Prince of Wales Hospital, Shatin, Hong Kong SAR, China. ${ }^{3}$ Hong Kong Institute of Diabetes and Obesity, The Chinese University of Hong Kong, The Prince of Wales Hospital, Shatin, Hong Kong SAR, China. ${ }^{4}$ Current Address: Department of Pediatrics, Section on Medical Genetics, and Centers for Human Genomics and Diabetes Research, Wake Forest University School of Medicine, NC, USA.

\section{Authors' contributions}

CT performed the statistical analysis and interpretation of data, and participated in drafting the manuscript. VL helped to perform the analysis and participated in coordination and acquisition of data. WS, RM, JC and MN conceived of the study, and participated in its design and coordination and helped to draft the manuscript. All authors read and approved the final manuscript.

\section{Received: 14 August 2009}

Accepted: 24 February 2010 Published: 24 February 2010

\section{References}

1. Reaven GM: Banting lecture 1988. Role of insulin resistance in human disease. Diabetes 1988, 37(12):1595-1607.

2. Executive Summary of The Third Report of The National Cholesterol Education Program (NCEP) Expert Panel on Detection, Evaluation, And Treatment of High Blood Cholesterol In Adults (Adult Treatment Panel III). Jama 2001, 285(19):2486-2497.

3. Malik S, Wong ND, Franklin SS, Kamath TV, L'Italien GJ, Pio JR, Williams GR: Impact of the metabolic syndrome on mortality from coronary heart disease, cardiovascular disease, and all causes in United States adults. Circulation 2004, 110(10):1245-1250.

4. Chen J, Muntner P, Hamm LL, Jones DW, Batuman V, Fonseca V, Whelton PK, He J: The metabolic syndrome and chronic kidney disease in U.S. adults. Annals of internal medicine 2004, 140(3):167-174.

5. Hanson RL, Imperatore G, Bennett PH, Knowler WC: Components of the "metabolic syndrome" and incidence of type 2 diabetes. Diabetes 2002, 51(10):3120-3127.

6. Ford ES, Giles WH, Dietz WH: Prevalence of the metabolic syndrome among US adults: findings from the third National Health and Nutrition Examination Survey. Jama 2002, 287(3):356-359.

7. Prevalence of the metabolic syndrome in populations of Asian origin. Comparison of the IDF definition with the NCEP definition. Diabetes research and clinical practice 2007, 76(1):57-67.

8. Thomas GN, Ho SY, Janus ED, Lam KS, Hedley AJ, Lam TH: The US National Cholesterol Education Programme Adult Treatment Panel III (NCEP ATP III) prevalence of the metabolic syndrome in a Chinese population. Diabetes research and clinical practice 2005, 67(3):251-257.

9. Cheung BM, Wat NM, Man YB, Tam S, Thomas GN, Leung GM, Cheng CH, Woo J, Janus ED, Lau CP, et al: Development of diabetes in Chinese with the metabolic syndrome: a 6-year prospective study. Diabetes care 2007, 30(6):1430-1436.

10. Thomas GN, Schooling CM, McGhee SM, Ho SY, Cheung BM, Wat NM, Janus ED, Lam KS, Lam TH: Metabolic syndrome increases all-cause and vascular mortality: the Hong Kong Cardiovascular Risk Factor Study. Clin Endocrinol (Oxf) 2007, 66(5):666-671.

11. Edwards KL, Austin MA, Newman B, Mayer E, Krauss RM, Selby JV: Multivariate analysis of the insulin resistance syndrome in women. Arterioscler Thromb 1994, 14(12):1940-1945. 
12. Anderson PJ, Critchley JA, Chan JC, Cockram CS, Lee ZS, Thomas GN, Tomlinson B: Factor analysis of the metabolic syndrome: obesity vs insulin resistance as the central abnormality. Int J Obes Relat Metab Disord 2001, 25(12):1782-1788.

13. Chan JC, Cheung JC, Lau EM, Wooa J, Chan AY, Swaminathan R, Cockrama CS: The metabolic syndrome in Hong Kong Chinese. The interrelationships among its components analyzed by structural equation modeling. Diabetes care 1996, 19(9):953-959.

14. Meigs JB, D'Agostino RB Sr, Wilson PW, Cupples LA, Nathan DM, Singer DE: Risk variable clustering in the insulin resistance syndrome. The Framingham Offspring Study. Diabetes 1997, 46(10):1594-1600.

15. Leyva F, Godsland IF, Ghatei M, Proudler AJ, Aldis S, Walton C, Bloom S, Stevenson JC: Hyperleptinemia as a component of a metabolic syndrome of cardiovascular risk. Arteriosclerosis, thrombosis, and vascular biology 1998, 18(6):928-933.

16. Kekalainen P, Sarlund H, Pyorala K, Laakso M: Hyperinsulinemia cluster predicts the development of type 2 diabetes independently of family history of diabetes. Diabetes care 1999, 22(1):86-92.

17. Lempiainen P, Mykkanen L, Pyorala K, Laakso M, Kuusisto J: Insulin resistance syndrome predicts coronary heart disease events in elderly nondiabetic men. Circulation 1999, 100(2):123-128.

18. Sakkinen PA, Wahl P, Cushman M, Lewis MR, Tracy RP: Clustering of procoagulation, inflammation, and fibrinolysis variables with metabolic factors in insulin resistance syndrome. American journal of epidemiology 2000, 152(10):897-907.

19. Li JK, Ng MC, So WY, Chiu CK, Ozaki R, Tong PC, Cockram CS, Chan JC: Phenotypic and genetic clustering of diabetes and metabolic syndrome in Chinese families with type 2 diabetes mellitus. Diabetes Metab Res Rev 2006, 22(1):46-52.

20. Ng MC, So WY, Cox NJ, Lam VK, Cockram CS, Critchley JA, Bell Gl, Chan JC: Genome-wide scan for type 2 diabetes loci in Hong Kong Chinese and confirmation of a susceptibility locus on chromosome 1q21-q25. Diabetes 2004, 53(6):1609-1613.

21. Ng MC, So WY, Lam VK, Cockram CS, Bell Gl, Cox NJ, Chan JC: Genomewide scan for metabolic syndrome and related quantitative traits in Hong Kong Chinese and confirmation of a susceptibility locus on chromosome 1q21-q25. Diabetes 2004, 53(10):2676-2683.

22. Arya R, Blangero J, Williams K, Almasy L, Dyer TD, Leach RJ, O'Connell P, Stern MP, Duggirala R: Factors of insulin resistance syndrome-related phenotypes are linked to genetic locations on chromosomes 6 and 7 in nondiabetic mexican-americans. Diabetes 2002, 51(3):841-847.

23. Tang W, Miller MB, Rich SS, North KE, Pankow JS, Borecki IB, Myers RH, Hopkins PN, Leppert M, Arnett DK: Linkage analysis of a composite factor for the multiple metabolic syndrome: the National Heart, Lung, and Blood Institute Family Heart Study. Diabetes 2003, 52(11):2840-2847.

24. Ott J, Rabinowitz D: A principal-components approach based on heritability for combining phenotype information. Human heredity 1999 , 49(2):106-111.

25. von Wowern F, Bengtsson K, Lindgren CM, Orho-Melander M, Fyhrquist F, Lindblad U, Rastam L, Forsblom C, Kanninen T, Almgren P, et al: A genome wide scan for early onset primary hypertension in Scandinavians. Human molecular genetics 2003, 12(16):2077-2081.

26. Liu W, Zhao W, Chase GA: Genome scan meta-analysis for hypertension. Am J Hypertens 2004, 17(12 Pt 1):1100-1106.

27. Rich SS, Bowden DW, Haffner SM, Norris JM, Saad MF, Mitchell BD, Rotter Jl, Langefeld CD, Hedrick CC, Wagenknecht LE, et al: A genome scan for fasting insulin and fasting glucose identifies a quantitative trait locus on chromosome 17p: the insulin resistance atherosclerosis study (IRAS) family study. Diabetes 2005, 54(1):290-295.

28. Freedman BI, Rich SS, Sale MM, Heiss G, Djousse L, Pankow JS, Province MA, Rao DC, Lewis CE, Chen YD, et al: Genome-wide scans for heritability of fasting serum insulin and glucose concentrations in hypertensive families. Diabetologia 2005, 48(4):661-668.

29. Badzioch MD, Igo RP Jr, Gagnon F, Brunzell JD, Krauss RM, Motulsky AG, Wijsman EM, Jarvik GP: Low-density lipoprotein particle size loci in familial combined hyperlipidemia: evidence for multiple loci from a genome scan. Arteriosclerosis, thrombosis, and vascular biology 2004, 24(10):1942-1950.
30. Perusse L, Rice T, Chagnon YC, Despres JP, Lemieux S, Roy S, Lacaille M, HoKim MA, Chagnon M, Province MA, et al: A genome-wide scan for abdominal fat assessed by computed tomography in the Quebec Family Study. Diabetes 2001, 50(3):614-621.

31. Jacobson P, Rankinen T, Tremblay A, Perusse L, Chagnon YC, Bouchard C: Resting metabolic rate and respiratory quotient: results from a genomewide scan in the Quebec Family Study. Am J Clin Nutr 2006, 84(6):1527-1533.

32. Palmer LJ, Buxbaum SG, Larkin E, Patel SR, Elston RC, Tishler PV, Redline S: A whole-genome scan for obstructive sleep apnea and obesity. American journal of human genetics 2003, 72(2):340-350.

33. Das SK, Elbein SC: The search for type 2 diabetes susceptibility loci: the chromosome 1q story. Current diabetes reports 2007, 7(2):154-164.

34. Demenais F, Kanninen T, Lindgren CM, Wiltshire S, Gaget S, Dandrieux C, Almgren $P$, Sjogren $M$, Hattersley A, Dina $C$, et al: A meta-analysis of four European genome screens (GIFT Consortium) shows evidence for a novel region on chromosome 17p11.2-q22 linked to type 2 diabetes. Human molecular genetics 2003, 12(15):1865-1873.

35. Arya R, Duggirala R, Almasy L, Rainwater DL, Mahaney MC, Cole S, Dyer TD, Williams K, Leach RJ, Hixson JE, et al: Linkage of high-density lipoproteincholesterol concentrations to a locus on chromosome 9p in Mexican Americans. Nature genetics 2002, 30(1):102-105.

36. Kalmyrzaev B, Aldashev A, Khalmatov M, Polupanov A, Jumagulova A, Mamanova L, Wilkins MR, Town M: Genome-wide scan for premature hypertension supports linkage to chromosome 2 in a large Kyrgyz family. Hypertension 2006, 48(5):908-913.

37. Bell JT, Wallace C, Dobson R, Wiltshire S, Mein C, Pembroke J, Brown M, Clayton D, Samani N, Dominiczak A, et al: Two-dimensional genome-scan identifies novel epistatic loci for essential hypertension. Human molecular genetics 2006, 15(8):1365-1374.

38. Gans RO, Donker AJ: Insulin and blood pressure regulation. J Intern Med Suppl 1991, 735:49-64.

39. Guimaraes S, Moura D: Vascular adrenoceptors: an update. Pharmacol Rev 2001, 53(2):319-356.

40. Anand-Srivastava MB: Atrial natriuretic peptide-C receptor and membrane signalling in hypertension. J Hypertens 1997, 15(8):815-826.

41. Ahlgren U, Pfaff SL, Jessell TM, Edlund T, Edlund H: Independent requirement for ISL1 in formation of pancreatic mesenchyme and islet cells. Nature 1997, 385(6613):257-260.

42. Despres JP, Lemieux I: Abdominal obesity and metabolic syndrome. Nature 2006, 444(7121):881-887.

43. Bosse Y, Despres JP, Chagnon YC, Rice T, Rao DC, Bouchard C, Perusse L, Vohl MC: Quantitative trait locus on $15 q$ for a metabolic syndrome variable derived from factor analysis. Obesity (Silver Spring) 2007, 15(3):544-550.

44. Grant SF, Thorleifsson G, Reynisdottir I, Benediktsson R, Manolescu A, Sainz J, Helgason A, Stefansson H, Emilsson V, Helgadottir A, et al: Variant of transcription factor 7-like 2 (TCF7L2) gene confers risk of type 2 diabetes. Nature genetics 2006, 38(3):320-323.

45. Helgadottir A, Manolescu A, Thorleifsson G, Gretarsdottir S, Jonsdottir H, Thorsteinsdottir U, Samani NJ, Gudmundsson G, Grant SF, Thorgeirsson G, et al: The gene encoding 5-lipoxygenase activating protein confers risk of myocardial infarction and stroke. Nature genetics 2004, 36(3):233-239.

46. Steinthorsdottir $V$, Thorleifsson G, Reynisdottir I, Benediktsson R, Jonsdottir T, Walters GB, Styrkarsdottir U, Gretarsdottir S, Emilsson V, Ghosh $S$, et al: A variant in CDKAL1 influences insulin response and risk of type 2 diabetes. Nature genetics 2007, 39(6):770-775.

47. Wang WY, Barratt BJ, Clayton DG, Todd JA: Genome-wide association studies: theoretical and practical concerns. Nat Rev Genet 2005, 6(2):109-118.

48. Boehnke M, Cox NJ: Accurate inference of relationships in sib-pair linkage studies. American journal of human genetics 1997, 61(2):423-429.

49. McPeek MS, Sun L: Statistical tests for detection of misspecified relationships by use of genome-screen data. American journal of human genetics 2000, 66(3):1076-1094.

50. O'Connell JR, Weeks DE: PedCheck: a program for identification of genotype incompatibilities in linkage analysis. American journal of human genetics 1998, 63(1):259-266. 
51. Abecasis GR, Cherny SS, Cookson WO, Cardon LR: Merlin-rapid analysis of dense genetic maps using sparse gene flow trees. Nature genetics 2002, 30(1):97-101.

52. Almasy L, Blangero J: Multipoint quantitative-trait linkage analysis in general pedigrees. American journal of human genetics 1998, 62(5):1198-1211

doi:10.1186/1471-2156-11-14

Cite this article as: Tam et al:: Genome-wide linkage scan for factors of metabolic syndrome in a Chinese population. BMC Genetics 2010 11:14.

Submit your next manuscript to BioMed Central and take full advantage of:

- Convenient online submission

- Thorough peer review

- No space constraints or color figure charges

- Immediate publication on acceptance

- Inclusion in PubMed, CAS, Scopus and Google Scholar

- Research which is freely available for redistribution

Submit your manuscript at www.biomedcentral.com/submit
C Biomed Central 